\title{
Awareness About Sharps Disposal Leads to Significant Improvement in Healthcare Safety: an Audit of Compliance in the National Health Service During the COVID-19 Pandemic
}

\author{
Asfa Hussain $^{1} \cdot$ Yusra Shah $^{1} \cdot$ Pradyumna Raval $^{1}$ (D) $\cdot$ Nicholas Deroeck $^{1}$
}

Accepted: 27 October 2020 / Published online: 31 October 2020

(C) Springer Nature Switzerland AG 2020

\begin{abstract}
Needle-stick injuries (NSIs) pose serious health risks and can transmit blood-borne diseases (BBDs), such as hepatitis B virus, hepatitis $\mathrm{C}$ virus, and human immunodeficiency virus from the patient to the staff member. The purpose of this study was evaluation of appropriate and safe disposal of sharps within a 730-bed acute district general hospital (DGH) in the UK. One hundred sharps containers were audited in November 2019 to assess whether they complied with the health and safety regulations across surgical, medical, and acute wards. Meetings with the appropriate staff members were organised and posters placed throughout the hospital to raise awareness. One hundred twenty-five sharps containers were re-audited in July 2020, in the midst of the COVID-19 pandemic to ascertain if there was an improvement. In November 2019, a total of 56\% of sharps containers were overfilled and hence were non-compliant with safety regulations. A re-audit performed in July 2020 found only $17 \%$ of sharps containers to be overfilled, which was a significant improvement $(p=0.0064)$ in practice. We noted that the overall compliance improved from being $44 \%$ in 2019 to 82.64 in the year 2020. This audit showed a significant improvement in the compliance of sharps bin containers in a DGH, signifying the increased awareness. It is necessary to audit sharps management regularly to accurately assess practice and prevent exposure to BBDs.
\end{abstract}

Keywords Sharps $\cdot$ Containers $\cdot$ Compliance $\cdot$ Re-audit $\cdot$ Needle-stick injuries $\cdot$ NSIs $\cdot$ Disposal $\cdot$ National Health Service $\cdot$ NHS

\section{Introduction}

Approximately 40,000 needle-stick injuries (NSIs) are reported annually, not accounting for unreported incidents - therefore, the true number of NSIs is potentially far higher [1]. The 2003 National Audit Office (NAO) report highlighted the risk of NSIs in the National Health Service (NHS). NSIs befall mostly nurses and doctors. However, ancillary staffs such as porters and cleaners are also affected. Around $40 \%$ of injuries are to a secondary individual [2].

A considerable limitation of the NHS is staff shortagesone of the reasons for this is staff sickness. Annual costs to the

Asfa Hussain and Yusra Shah are joint first authors.

This article is part of the Topical Collection on Covid-19

Pradyumna Raval

raval.prashant@gmail.com

1 Department of Trauma and Orthopaedics, Lister Hospital, Stevenage SG1 4AB, UK
NHS are an estimated $£ 1$ billion [2]. NSIs pose serious health risks and can transmit blood-borne diseases (BBDs), such as hepatitis $B$ virus (1 in 3), hepatitis C virus (1 in 50), and human immunodeficiency virus ( 1 in 300) from the patient to the staff member $[1,3]$ The infection risk depends on the viral load of the patient and the volume of blood product that infects the individual [1] NSIs can cause psychological trauma for the affected individual, even if BBDs are not transmitted [4].

NHS resolution stated that NSIs are largely preventable and employers are legally required to take measures to protect their staff. Major causes of NSIs include overfilled sharps bins, inadequate disposal, non-compliance, and not using PPE (personal protective equipment) [5]. Aziz et al. [3] identified that the clinician should verify the correct size of sharps bin before use, and ensure that the needle/syringe used fits appropriately into the sharps container to prevent NSIs. Sharps containers must only be filled to the marked line and closed immediately after this line is reached. The risk of injury is increased once the container is overfilled. 
For this audit, we focused on appropriate and safe disposal of sharps. The compliance of sharps bins within a 730-bed acute district general hospital (DGH), The Lister Hospital, Stevenage, was assessed and recommendations for improving safety were suggested.

\section{Methodology}

In November 2019, 100 sharps bins were audited throughout Lister Hospital to determine whether they were compliant with health and safety standards. Several parameters were examined: size of the container, ward, specific location, level (above/ below/at the level), date the bin was inspected, and the date the bin was first used.

The specific locations noted included preparation rooms, sluices, nurses' stations, and resuscitation areas. The majority of the departments within the DGH were reviewed including medical, surgical, and acute wards, on a random date and time in November 2019. If a sharps container was above or at marked level and still in use, it was noted as being noncompliant.

Following the initial audit in November 2019, a presentation was made at the Lister orthopaedic multi-disciplinary team (MDT) audit meeting, in February 2020. This meeting consisted of nurses, healthcare workers, and doctors, with the aim of raising awareness of the issue and obtaining feedback on how to ensure change was implemented. One of the suggestions was to set up posters around the hospital to raise awareness.

Informal meetings with staff members, focusing on nurses and doctors, were held to remind them of the risk of overfilled sharps containers. The infection risks and psychological effects of NSIs were discussed, and preventative measures were detailed. Additionally, the risks to ancillary workers were discussed in depth. Posters were set up around the hospital, in the treatment and sluice rooms, above the sharps containers. These posters focused on three categories: 'dangers of sharps', 'safe handling', and 'managing a needle-stick injury'. This poster can be seen in Fig. 1.

In July 2020, 125 sharps bins were re-audited, in the midst of the COVID-19 pandemic, to determine whether there was an improvement. The same methodology was used in July 2020, as in November 2019, to ensure conformity of data. Again, the majority of the departments were checked, including medical and surgical wards. The results were then presented at the Lister orthopaedic MDT meeting.

\section{Statistical Analysis}

A statistical analysis was conducted using IBM SPSS software package version 21. The Fisher's exact test was performed to compare the compliance before and after the intervention. A difference was considered statistically significant when the probability $(p)$ value was $<0.05$.

\section{Results}

A total of 100 sharps containers in November 2019 and 125 in July 2020 were reviewed, across medical, surgical, and acute wards at The Lister Hospital. In November 2019, a total of $56 \%$ of sharps containers were overfilled and hence were noncompliant with safety regulations. A re-audit performed in July 2020 found only $17 \%$ of sharps containers to be overfilled, which was a significant improvement $(p=$ 0.0064 ) in practice. We noted that the overall compliance improved from being 44\% in 2019 to 82.64 in the year 2020 .

Table 1 compares the compliance of various sizes of sharps containers in 2019 with 2020. Sharps containers above or at the marked level were noted as non-compliant. The largest improvement was seen in $9 \mathrm{~L}$ containers, followed closely by $2-3 \mathrm{~L}$ and $17-18 \mathrm{~L}$ containers. Improvement was seen across all sizes, with the minimum percentage improvement in $5 \mathrm{~L}$ containers at $37 \%$.

Table 2 compares the percentage compliance of sharps containers in different locations within the ward: the

DANGER OF SHARPS
Hepatitis B
Hepatitis C
HIV

SAFE HANDLING
Always wear gloves when
handling sharps
Never re-sheath needles by
hand
Dispose of sharps straight after
use
Always dispose of sharps in a
suitable bin
Never fill sharps bins above the
marked line

MANAGING A NEEDLESTICK INJURY

Squeeze the area around the injury to allow it to bleed Hold the punctured skin under running water for a few minutes and wash with soap Cover with a waterproof plaster

Fig. 1 Danger of NSIs' poster, with information on safe handling and management of an injury 
Table 1 The percentage compliance of various sizes of sharps containers in litres (L) in November 2019 and July 2020, with the percentage improvement

\begin{tabular}{|c|c|c|c|}
\hline \multirow[t]{2}{*}{ Sharps container size } & \multicolumn{2}{|c|}{ Percentage compliance $(\%)$} & \multirow[t]{2}{*}{ Percentage improvement (\%) } \\
\hline & Nov 2019 & July 2020 & \\
\hline$<1 \mathrm{~L}$ & 47 & 96 & 49 \\
\hline $2-3 \mathrm{~L}$ & 38 & 96 & 58 \\
\hline $5 \mathrm{~L}$ & 50 & 87 & 37 \\
\hline $9 \mathrm{~L}$ & 0.25 & 60 & 59.79 \\
\hline $17-18 \mathrm{~L}$ & 23 & 81 & 58 \\
\hline $22 \mathrm{~L}$ & 50 & 100 & 50 \\
\hline $32 \mathrm{~L}$ & 50 & 88 & 38 \\
\hline
\end{tabular}

preparation room, resuscitation trolleys, sluice, nursing station, and consultation rooms. The nurses' station is shown to have a slight improvement of $2 \%$, whilst a significant improvement of $49 \%$ is seen in the preparation rooms.

Prior to COVID-19 in November 2019, the surgical wards were adhering more to the safety recommendations, and appropriately filling their sharps containers in comparison to the medical wards. This changed during the COVID-19 pandemic, as medical wards became more stringent in adhering to the guidelines. This is demonstrated in Table 3, and the medical wards saw a greater increase in compliance.

The container itself should be labelled correctly, with the date the container was first used, and when it is closed [3]. Only $7 \%$ of bins inspected were not filled in correctly-for example missing the start date, in July 2020 compared to $26 \%$ in 2019.

\section{Discussion}

Sharps should be disposed of as a single unit; hence, the needle and syringe should remain attached when placed into the sharps container. Aziz et al. [3] emphasised the importance of using the appropriate-sized sharps container for safe handling. An unnecessarily large or small container for the needle/ syringe could increase risk of injuries and thus infections.

Transporting sharps throughout a ward without a portable $<1 \mathrm{~L}$, or 2-3 L container will increase the risks of NSIs. The location of the containers is vital, and they should be easily accessible to those who need it, to protect staff and patients [3]. The preparation room is where nurses and doctors prepare equipment for medications, bloods, and cannulas. Portable sharps containers are usually taken onto the ward with the sharps, and therefore stored in the preparation room until they are filled. NSI awareness posters were frequently displayed in the preparation rooms, and may also factor into why the largest improvement in compliance is seen here.

In a recent article on needle-stick injuries by King and Strony [6], various unsafe practices such as re-sheathing of needles and how to avoid a potential needle-stick injury have been discussed. The article once again emphasises the importance of educating staff members, both medical personnel as well as ancillary staff in order to avoid NSI's. This article not only discusses about the safe practices which an institution should implement but also informs the reader about common blood-borne infections and their management.

The re-audit was carried out in July 2020, in the midst of the COVID-19 pandemic. At The Lister Hospital, the medical wards had a greater number of COVID-19 patients than the surgical wards, and we believe that this is an additional factor behind increased compliance in July 2020, alongside our posters and staff meetings.

A limitation of the study is that due to COVID-19, the hospital was undergoing constant changes, and hence some of the wards reviewed in 2019 were not open at the time of the data collection in July 2020. Random dates and times were

Table 2 The percentage compliance of sharps containers in different locations within the ward in November 2019 compared with July 2020

\begin{tabular}{llll}
\hline Location & Percentage compliance (\%) & Percentage improvement (\%) \\
\cline { 2 - 4 } & Nov 2019 & July 2020 & \\
\hline Preparation room & 41 & 90 & 49 \\
Resus & 57 & 100 & 43 \\
Sluice & 50 & 86 & 36 \\
Nursing station & 48 & 50 & 2 \\
\hline
\end{tabular}


Table 3 Compliance shown in different ward types: surgical and medical

\begin{tabular}{llll}
\hline Ward type & \multicolumn{2}{c}{ Percentage compliance (\%) } & Percentage improvement (\%) \\
\cline { 2 - 3 } & Nov 2019 & July 2020 & \\
\hline Surgical & 53 & 81 & 28 \\
Medical & 43 & 92 & 49 \\
\hline
\end{tabular}

chosen for each audit to prevent bias, and the quantity of containers varied on each date.

When discussing the factors that increase NSIs and prevention methods, we were met with some resistance, as some staff members felt this was condescending. The posters aided a great deal, as they ensured a visual reminder was present, and that staff members could read this later at a suitable pace.

To continue to raise awareness, a suggestion is that the Trust emails staff monthly and highlights the importance of safe disposal and handling of sharps, and the significance of reporting NSIs. Regular training is also vital; therefore, staff could have an e-learning module to complete each year on NSIs [3].

\section{Conclusion}

Correct disposal of sharps is vital to prevent NSI's and BBDs. The duty lies on the medical professional to ensure that the correct sharps container is used for the sharp object, and to keep the container in close proximity to the sharps $[1,3]$.

An injury can be mentally and physically detrimental to the persons involved, and take a toll on the NHS, for example by reducing staff numbers due to preventable injuries $[2,5]$. This audit showed a significant improvement in the compliance of sharps bin containers in a DGH, signifying that increased awareness helped prevent NSIs. A suggestion is that hospitals replicate this audit twice a year to improve compliance and continue to raise awareness.
Authors' Contributions (a) AH and YS - Joint first authors. Data collection, analysis and write-up

(b) PR-Basic concept of audit, review of manuscript and revision of manuscript

(c) ND - Senior author overviewing the entire project

Data Availability Not applicable.

\section{Compliance with Ethical Standards}

Conflict of Interest The authors declare that they have no conflict of interest.

Ethics Approval Not applicable.

Consent to Participate Not applicable.

Consent for Publication Not applicable.

Code Availability Not applicable.

\section{References}

1. Elmiyeh B, Whitaker IS, James MJ, Chahal CA, Galea A, Alshafi K. Needle-stick injuries in the National Health Service: a culture of silence. J R Soc Med. 2004;97(7):326-7.

2. National Audit Office. A safer place to work: improving the Management of Health and Safety Risks to staff in NHS trusts report by the comptroller and auditor general HC 623 session 2002-2003 30 April 2003. Stationery Office; 2003.

3. Aziz AM, Ashton H, Pagett A, Jones S, Mullin B. Sharps management in hospital: an audit of equipment, practice and awareness. Br J Nurs. 2009;18(2):92-8.

4. Blenkharn JI. Sharps management and the disposal of clinical waste. Br J Nurs. 2009 Jul 23;18(14):860-4.

5. NHS resolution. Did you know? Preventing needlestick injuries. $1^{\text {st }}$ ed. [pdf]. Available at: https://resolution.nhs.uk/wp-content/uploads/ 2017/05/NHS-Resolution-Preventing-needlestick-injuries-leafletfinal.pdf. Accessed 19 Aug. 2020.

6. King KC, Strony R. StatPearls [Internet]. Treasure Island: StatPearls Publishing; 2020. Needlestick

Publisher's Note Springer Nature remains neutral with regard to jurisdictional claims in published maps and institutional affiliations. 